\title{
Delayed Presentation Of Missed Vascular Injuries And Pitfalls In Primary Treatment- Experience Of A Vascular Surgery Unit In Pakistan
}

\author{
Ahsin Manzoor Bhatti, Junaid Mansoor, Haroon Sabir Khan
}

ABSTRACT:

Objective: To analyze errors in primary treatment of vascular injuries and delayed presentations of missed vascular injuries as a surrogate indicator of need for improved vascular surgical training of upcoming general surgeons.

Materials and methods: This retrospective observational study was carried out at vascular surgery department of two tertiary care hospitals of Armed Forces from Jan 2012 to June 2017. Hospital records of all patients with vascular trauma were analyzed for presence of pitfalls in primary treatment and delayed presentation of missed vascular injuries which resulted in redo surgeries or adverse outcomes.

Results: Out of 256 patients with vascular injury sequel 41 had either a problem in primary treatment or presented with delayed complications of missed injuries. The omissions can be divided into: missed injuries (24/41), technical errors in initial repair (12/24), reperfusion of mangled Extremity (3/41) and non availability of a surgeon capable of undertaking vascular repair. The commonest operative fault was failure to debride the vessel adequately and vascular repair under tension. The commonest primary assessment problem was failure to timely appreciate hard signs of vascular injury.

Conclusion: With better training and emphasizing the need of thorough clinical examination outcome of vascular trauma can be improved.

Key words: delayed, injuries, missed, presentation, vascular.

- - - - - - - - - - - - - - - - - - - - - - - - - - - - -

\section{INTRODUCTION:}

Vascular trauma is an important component of the rapidly emerging trauma pandemic. The mechanism and pattern of vascular injuries differs in various parts of the world and they will vary in the same community in war and peace. Great majority of these injuries are due to penetrating trauma, with stab, gunshot wounds and road traffic accidents being the most common cause ${ }^{1-4}$.

Previously major vascular injuries were either uniformly fatal or led to major amputations. Important lessons learnt during first and second world wars in diagnosis and management of vascular injuries and improvement in vascular repairing techniques pioneered by surgeons such as Carrell, lead to introduction of improved vascular reconstructive methods during the Korean and Vietnam wars with tremendous reduction in amputation rates and improved survival $^{2-5}$. Now the extremity vascular trauma ranks among the leading causes of preventable deaths $\mathrm{s}^{6-8}$. However, a missed or inappropriately treated vascular injury can lead

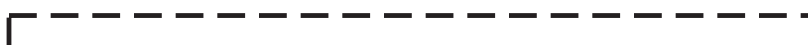

Ahsin Manzoor Bhatti

Professor of Surgery,

I HOD Vascular Surgery Unit, CMH Quetta,

IEmail: ahsinmb@yahoo.com

I Junaid Mansoor

Clinical Fellow HPB Surgery,

Kings College Hospital, London, UK

I

Haroon Sabir Khan

Associate Professor, Urology dept,

I PNS Shifa Karachi

Received: 17-09-18

I Accepted: 19-10-18

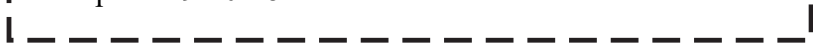

to limb loss or potentially serious sequel like pseudo aneurysms or traumatic arteriovenous fistula $\mathrm{e}^{9-11}$.

In Pakistan, vascular Surgery is still in its infancy and there are only a few centers with dedicated vascular surgery departments. Except for two or three centers, there is no formal training of surgical trainees in this important specialty, resulting in a vacuum in management of vascular trauma. The purpose of this article is to share our experience of delayed presentation of vascular injuries and the lapses in the initial management of vascular trauma patients referred to our unit as well as to highlight the need for more structured training in this specialty. A brief overview of recommended management strategies is also provided to serve as a guide for those involved in the management of these critically injured patients.

\section{PATIENTS AND METHODS:}

This is a retrospective descriptive study, carried out at two tertiary care hospitals with vascular surgery departments. Approval from Institutional Ethics Review Board was taken. Hospital records of all the acute vascular trauma patients treated at vascular surgery department from Jan 2012 to June 2017 as well as those operated upon for complications of previous vascular trauma during the same period were retrieved manually and analyzed. All the patients with a lapse in primary management of vascular injury were included in the study.

For the purpose of description we divided the patients into those presenting acutely with a lapse in primary management resulting in a need for re-exploration to save life or limb and those patients presenting late, with a complication of previously missed or mismanaged vascular injury like 
presence of pseudo aneurysm, traumatic arteriovenous fistula (AVF) or ischaemia. Those patients with a documented successfully repaired vascular trauma before referral were excluded from the study as well as those repaired in our department not requiring re-exploration.

The records were analyzed to find the cause of poor outcome. The various shortcomings to be analyzed were divided into: delayed presentations of missed vascular injury, missed hard signs, missed compartment syndromes, errors in operative management and non-availability of appropriately trained surgeon.

\section{RESULTS:}

During the study period a total of 286 patients presented to our department with vascular trauma or its sequel. A total of 41 patients fulfilled the inclusion criterion and their records were further analyzed. Details of the patients are listed in table- 1 . The patients consisted of 38 males (93\%) and 3 females $(7 \%)$ with a mean age of $24 \pm 12.6$ years (range 18 78 years). The lower limb vascular extremity trauma $(n=32)$ outnumbered the upper extremity trauma $(\mathrm{n}=8)$. Superficial femoral artery $(\mathrm{n}=18)$ was the commonest injured vessel.

All of these patients were either referred from other hospitals or have been under care of another specialty and then referred to us. Road traffic accident (RTA) and firearm injuries were the commonest causes of extremity vascular injury (17 cases each).

The injuries and lapses in initial management can be divided into following groups:

1. Missed Vascular Injuries (24/41 patients)

a) Missed Soft Signs (15/41 patients): Fifteen patients presented with delayed presentations of missed vascular injuries ( 7 had pseudo aneurysms and 8 patients presented with traumatic arteriovenous fistulas). Pseudo aneurysms presented earlier (latest by 12 months) after primary injury than did the traumatic arterio-venous fistulas (up to 20 years post injury).

b) Missed Hard Signs (7/41 patients): Hard signs of vascular trauma were missed in 7 patients. All of them lost their limbs.

c) Missed Compartment Syndrome (2/41): In two patients compartment syndrome was missed, both of them lost the limbs.

2. Technical Errors in Primary Repair (12/41 patients): Following technical errors were observed in the initial vascular repair.

a) Inadequate Debridement of injured vessel (4/12 patients): In four of the patients the damaged vessel was not debrided appropriately. The damaged ends of vessels were either sewed together (two patients) resulting in exposed thrombogenic deeper layer, which led to thrombosis or a thrombectomy had been done (two patients) using a fogarty catheter. Two of these patients reached our department early and they were operated again with debridement and interposition vein graft, resulting in limb survival.

b) Repair Under tension (6/12 patients): In six patients we found that primary repair was done under tension resulting in thrombosis of vessel. This results in graft failure. Three of these patients had major amputations.

c) Use of Prosthetic graft (2/12 patients). In two patients a prosthetic graft had been used despite the availability of native vein. In one patient the graft was $4 \mathrm{~mm}$ which was used to bridge the gap between damaged subclavian artery. This was thrombosed when the patient arrived in our unit. The graft was replaced with saphenous vein. In other patient a $6 \mathrm{~mm}$ graft was used to repair popliteal artery. It was also removed and replaced with native vein. Both limbs survived ultimately.

3. Reperfusion of mangled extremity: In the presence of extensive musculoskeletal trauma and vascular injuries it may not be a good idea to repair the artery. The chances of blow out of graft are quite high and if the limb survives, it may be a painful, non functional and anaesthetic limb with recurrent wound infections (11). In our series we had two patients with such limbs. All of them had graft blow out between 5 th -8 th days and despite attempts at redo of bypass at extra anatomical site, it resulted ultimately in limb loss.

4. Non availability of Surgeon with experience in vascular repair: There were two patients who had arterial injury, which was picked up early, but they lost their limbs because no one was willing to take up the daunting task of arterial repair. By the time they reached at a hospital with adequate facilities it was too late.

A summary of these lapses and outcomes is shown in table no 2 .

\section{DISCUSSION:}

Major arterial injury poses a challenge to the operating team and is a nightmare for the untrained. The surgical treatment should be based on principles of thorough wound examination and debridement, vascular repairs to restore perfusion as well as fracture stabilization when required. In a polytrauma patient there is a high chance that a vascular injury may be missed $^{12-13}$. Unrecognized or poorly treated arterial trauma has serious consequences of life and limb loss, as evident in present series where failure to timely recognize hard signs of vascular injury had led to loss of 7 out of 9 limbs, technical errors in operative management lead to loss of 5 limbs out of 12 limbs where the arterial repair was technically not sound.

The presence of a "hard" sign of vascular injury mandates an immediate surgical exploration and vascular repair ${ }^{14-16}$. Unless other skeletal injuries are suspected no imaging is 


\begin{tabular}{|l|l|}
\hline Total Number of Patients & 41 \\
\hline Gender M : F & $38: 3$ \\
Mean Age & $24 \pm 12.6$ (Range: \\
(years) \pm SD & $18-78$ years) \\
\hline Region injured & $32(78)$ \\
Lower limb, n (\%) & $8(20)$ \\
Upper limb, n (\%) & $1(2$ \\
Neck n, (\%) & \\
\hline Vessel Injured & $18(44)$ \\
Superficial femoral artery n (\%) & $4(10)$ \\
Common femoral artery n (\%) & $1(2)$ \\
Profunda femoris artery n (\%) & $8(20)$ \\
Popliteal artery n (\%) & $1(2)$ \\
Peroneal artery n (\%) & $5(12)$ \\
Brachial artery n (\%) & $2(5)$ \\
Subclavian artery n (\%) & $1(2)$ \\
Radial / Ulnar artery n (\%) & $1(2)$ \\
Vertebral artery n (\%) & \\
\hline
\end{tabular}

Table 1: Demographic details of the patients

\begin{tabular}{|l|l|l|}
\hline \multicolumn{1}{|c|}{ Lapses } & \multicolumn{1}{c|}{ Detail } & \multicolumn{1}{c|}{ Outcome } \\
\hline \multirow{2}{*}{ Missed Vascular Injuries (24/41) } & Missed Soft Signs (15/24) & All limbs saved \\
\cline { 2 - 3 } & $\begin{array}{l}\text { Missed Hard Signs (7/24) } \\
\text { Missed Compartment Syndrome } \\
\text { 2/24) }\end{array}$ & All of them had major amputations \\
\hline $\begin{array}{l}\text { Technical Error in initial management } \\
(12 / 41)\end{array}$ & $\begin{array}{l}\text { Repair without debridement (2/12) } \\
\text { Only thrombectomy (2/12) } \\
\text { Repair under tension (6/12) } \\
\text { Use of prosthetic graft (2/12) }\end{array}$ & $5 / 12$ limbs were lost \\
\hline $\begin{array}{l}\text { Reperfusion of mangled Extremity } \\
(3 / 41)\end{array}$ & $\begin{array}{l}\text { Extensive bone, soft tissue and } \\
\text { neurovascular injuries. High MESS } \\
\text { score, vascular repair was } \\
\text { nevertheless done }\end{array}$ & All of them lost limbs due to graft \\
blow out. \\
\hline $\begin{array}{l}\text { Non-availability of technically } \\
\text { competent surgeon (2/41) }\end{array}$ & $\begin{array}{l}\text { No surgeon in the local hospital } \\
\text { agreed to repair. Patients were referred } \\
\text { to other hospitals }\end{array}$ & Both of them lost the limbs. \\
\hline
\end{tabular}

Table 2: Details of Lapses and outcomes

required and perfusion should be restored within 6 hours of vascular injury ${ }^{14}$. Picking up of hard signs of vascular trauma should, in theory, be straightforward but in our series these were missed in 12 patients. This is quite surprising and points to the fact that there is a lack of 'vascular surgery perspective' at all levels of surgical training. All the doctors involved in care of injured patients need to be reminded again and again to check the distal neurovascular status. A penetrating injury in close proximity to a vessel may cause a partial injury to vessel wall, which may be missed due to presence of distal pulses and absent hard signs of vascular injury at initial presentation ${ }^{17-18}$. As the injured vessel thrombose over time, pulses become absent. Thus there is a need of repeated examination of distal pulses.

Soft signs of vascular trauma are easy to miss unless there is a high index of suspicion and could result in pseudo aneurysm, traumatic arteriovenous fistulas or delayed ischemia ${ }^{2}$. One of useful technique to check for arterial trauma in absence of hard signs is injured extremity index (IEI). It is like ankle brachial pressure index (ABPI) of injured limb compared it with uninjured limb. An index of less than 0.9 is associated with more than $90 \%$ chance of arterial injury 19-20. Computed tomographic angiography (CTA) is recommended as the primary diagnostic study for evaluation of penetrating 
lower extremity vascular injury ${ }^{7}$. Although duplex scan has a sensitivity of $95-99 \%$ and a specificity of $98-99 \%$, it is operator dependent8. There may be a role for these studies in patients with soft signs of vascular injury or with proximity injuries. We generally rely on Duplex Ultrasound scan followed by angiography in selected cases for detection of subtle arterial injury due to lack of sufficient resources. Non-operative observation of asymptomatic non-occlusive arterial injuries is acceptable7. Patients with normal physical examination findings and an IEI or ABI $>0.9$ may be discharged in absence of other injuries requiring admission $^{7,9,21}$. It is also important to remember that some missed vascular injuries may present years later with other symptomatology. Two out of eight of our patients who had post traumatic AVF were being treated for varicose veins while one was treated for lymphedema. This underscores the importance of a thorough history and complete physical examination. The hard and soft signs of vascular injuries should not be missed as they can be picked by a thorough clinical examination. We need to inculcate in out undergraduate and post graduates students the importance of a thorough clinical assessment in a poly trauma patient.

Popliteal artery injury in the form of transaction, laceration, perforation, occlusion, arteriovenous fistula, or intimal injury may follow blunt trauma to the lower extremity in up to $46 \%$ cases 22 . Up to $20 \%$ of limbs associated with knee dislocations and vascular injuries end up in amputations ${ }^{8}$. As evident in our series popliteal artery transaction or thrombosis associated with knee dislocations is easily missed (8 out of 41 cases). It may be due to primary concern for knee dislocation, lack of vascular trauma perspective, and overlooking the repeated vascularity examination after applying a POP cast. It is therefore of utmost importance to repeatedly assess distal pulses for up to 48 hours in cases of knee dislocation as intimal tears may cause thrombosis later ${ }^{12}$. If a patient with fracture has doubtful vascularity it is utmost important that all the bandages and plaster must be removed and then the vascularity reassessed. If hard signs are present then time should not be wasted in unnecessary investigations like Duplex ultrasonography or angiography and the wound should be explored.

The incidence of femoral artery pseudo aneurysm post catheterization is around 3\% with obesity, female gender, multiple puncture attempts and use of antiplatelet and anticoagulation therapy as independent risk factors ${ }^{23}$. We encountered two cases of pseudo aneurysm following insertion of dialysis catheter-one in femoral artery and the other in subclavian artery while one case was in an IV drug abuser. The two post-catheterization pseudo aneurysms were primarily repaired while the one in IV drug abuser had an extra-anatomical bypass due to infective field and extensive scarring in the area.

Although endovascular treatment options are increasingly used in many parts of the world, we use it only occasionally because of lack of facilities and expertise. Covered stents for pseudo aneurysm or arteriovenous fistulas and embolization for bleeding is being used successfully ${ }^{8}$. However, the routine use of endovascular therapies in acute post trauma settings following infra-inguinal trauma is not supported by data so far ${ }^{7}$.

The decision for open surgery should be made quickly. General principles for surgical repair of arterial injury are: proximal and distal control, debridement of damaged artery, embolectomy of proximal and distal artery followed by proximal and distal infusion of heparin and a tension free repair which should not result in constriction of lumen and the repair must be covered by sift tissues ${ }^{7}$. Simple arterial repairs fare better than grafts. If required, vein graft is the best choice. PTFE, however, is should be used with caution in contaminated fields ${ }^{7}$. We usually do not prefer synthetic grafts for arterial reconstructions in trauma patients; however we recommend its use when the size of venous graft does not match to the injured vessel. Prophylactic fasciotomies should be liberally performed prophylactically in ischemic limbs with delayed repairs.

We also found that technical errors in management of vascular injuries is common. Most common technical error that we found in 6 out of 12 cases is vascular repair under tension. There is a natural urge to mobilize the damaged vessel and to do the primary end to end anastomosis and in doing so the surgeon may compromise on resecting the damaged artery, resulting in apparent success but ultimately leads to thrombosis of the graft due to repair in damaged vessel wall as well as inadequate vessel lengths leading to tensioned repairs. Arterial repair with direct anastomosis fare poorer in blunt trauma or crush injury of a long vessel segment compared to those with penetrating injuries ${ }^{12}$.

As mentioned earlier in four patients the damaged vessel was not debrided appropriately. The damaged ends of vessels were either sewed together (two patients) resulting in exposed thrombogenic deeper layer, which led to thrombosis or a thrombectomy had been done (two patients) using a fogarty catheter. The reason for doing only thrombectomy was apparently 'normal' appearance of damaged vessel. Excessive stretching of an artery results in intimal tear which exposes deeper thrombogenic layer and leads to thrombosis and dissection of distal vessel. From the outside damaged thrombosed vessel appears normal and a less experienced surgeon may be deceived by this appearance, who therefore only opts for thrombectomy.

The use of temporary intravascular shunts (TIVSs) may be indicated to restore arterial flow in combined vascular/orthopedic injuries (Gustillo IIIC fractures) to facilitate limb perfusion during orthopedic stabilization. They are also valuable as a part of damage control surgery or to gain time if the facilities of arterial repair are not available $e^{7,24,25}$. They have been used extensively by the 
American forces in Iraq and Afghanistan and we find it useful in our experience as well. But a word of warning; it is utmost important that proximal and distal vessels must be cleared of all the clot and it should be flushed with heparinized saline before inserting a shunt. In addition kinking, dislodgement and pressure on the shunt can also result in ischemia.

\section{CONCLUSION:}

Many limbs and lives can be saved by a thorough clinical examination in a poly trauma patient. A high level of suspicion, in conjunction with the knowledge of sensitive and specific clinical signs, is paramount for an accurate and timely diagnosis. A thorough physical exam, including determination of the IEI, is crucial in the early assessment of a patient with concern for a vascular extremity injury. Adequate training of emerging general surgeon in recognition of vascular injury and its adequate repair is essential to save life and limb.

\section{REFERENCES:}

1. Jawas A, Abbas AK, Nazzal M, Albader M, Abu-Zidan FM. Management of war-related vascular injuries: experience from the second gulf war. World Journal of Emergency Surgery 2013;8(22):

2. Coimbra R, Hoyt D. Vascular Trauma: Epidemiology and Natural History. Rutherford's Vascular Surgery, 7th ed. Philadelphia: W.B. Saunders Company; 2010; pp 2312-2315.

3. Creagh T, Broe P, Grace P, Bouchier-Hayes D. Blunt trauma induced upper extremity vascular injuries J R Coll Surg Edinb. 1991.

4. Mattox K, Hirshberg A. Vascular trauma. Haimovici's Vascular Surgery, USA: Blackwell Science; 4th ed USA: , 1996; pp 480-96.

5. Razmadze A. Vascular injuries of the limbs: a fifteen-year Georgian experience. Eur J Vasc Endovasc Surg. 1999; 18(3): 235-9.

6. Rasmussen T, Clouse W, Jenkins D, Peck M, Eliason J, Smith D. Echelons of care and the management of wartime vascular injury: a report from the 332nd EMDG/AirForce Theater Hospital, Balad Air Base, Iraq. Perspect Vasc Surg Endovasc Ther. 2006.

7. Harbrecht BG, Miller KR, Motameni AT, Benns M V, Bozeman MC, Nash NA, et al. Gunshot Injuries to the Extremity: Is Immediate General Surgery Presence Needed? Am Surg [Internet]. 2018;84(9):1450-4.

8. Karaolanis G, Moris D, McCoy CC, Tsilimigras DI, Georgopoulos S, Bakoyiannis C. Contemporary Strategies in the Management of Civilian Abdominal Vascular Trauma. Front Surg [Internet]. 2018;19:5-7.

9. Rasmussen T, Stockinger Z, Antevil J, White C, Fernandez N, White J, et al. Wartime Vascular Injury. Mil Med. 2018;183: $101-4$.

10. Cooper N, Roshdy M, Sciarretta JD, Kaufmann C, Duncan $\mathrm{S}$, Davis J, et al. Multidisciplinary team approach in the management of popliteal artery injury. J Multidiscip Healthc. 2018; 11: 399-403.
11. Martin GE, He H, Makley AT, Pritts TA, Elterman JB, Johannigman JA, et al. Proximal penetrating extremity injuries-An opportunity to decrease overtriage? J Trauma Acute Care Surg [Internet]. 2018; 85(1): 122-7.

12. Perkins ZB, Yet B, Glasgow S, Cole E, Marsh W, Brohi K, et al. Meta-analysis of prognostic factors for amputation following surgical repair of lower extremity vascular trauma. Br J Surg [Internet]. 2015; 102(5): 436-50.

13. Moniz MP, Ombrellaro MP, Stevens SL, Freeman MB, Diamond DL, Goldman MH. Concomitant orthopedic and vascular injuries as predictors for limb loss in blunt lower extremity trauma. Am Surg [Internet]. 1997; 63(1): 24-8.

14. Fox N, Rajani RR, Bokhari F, Chiu WC, Kerwin A, Seamon $\mathrm{MJ}$, et al. Penetrating Lower Extremity Arterial Trauma, Evaluation and Management of. J Trauma. 2012;73(5):31520.

15. Patel KR, Rowe VL. Vascular Trauma: Extremity. In: Jack L. Cronenwett, Johnston KW, editors. Rutherford's vascular surgery. 2: W.B Saunders; 2010. p. 2361-73.

16. Chen J-L, Yang T-Y, Chuang P-Y, Huang T-W, Huang K-C. Pseudoaneurysm rupture with hemorrhagic shock in a patient with periprosthetic hip joint infection. Medicine (Baltimore) [Internet]. 2018; 97(26): e11028.

17. Dennis J, Frykberg E, Veldenz H, Huffman S, Menawat S. Validation of nonoperative management of occult vascular injuries and accuracy of physical examination alone in penetrating extremity trauma: 5- to 10 -year follow-up. J Trauma. 1998;44(2):243-52.

18. Kauvar DS, Sarfati MR, Kraiss LW. National trauma databank analysis of mortality and limb loss in isolated lower extremity vascular trauma. J Vasc Surg [Internet]. 2011;53(6):1598-603.

19. Siddique MK, Majeed S, Irfan M, Ahmad N. Missed Vascular Injuries: Presentation and Outcome. JCPSP. 2014;24(6):42831.

20 Rayamajhi S, Murugan N, Nicol A, Edu S, Klopper J, Naidoo $\mathrm{N}$, et al. Penetrating femoral artery injuries: an urban trauma centre experience. Eur J Trauma Emerg Surg

21. Rasmussen T, Fox C. Vascular Trauma: Military. Rutherford's Vascular Surgery, 7th ed. Philadelphia: W.B. Saunders Company; 2010.

22. Patterson B, Agel J, Swiontkowski M, Mackenzie E, Bosse $\mathrm{M}$. Knee dislocations with vascular injury: outcomes in the Lower Extremity Assessment Project (LEAP) Study. J Trauma. 2007;63(4):855-8.

23. Imerci A ÖK, Gürbüz Y, Sügün TS, Canbek U, Savran A. Popliteal Artery Injury Associated with Blunt Trauma to the Knee without Fracture or Dislocation. West J Emerg Med. 2014;15(2):145-8.

24. Abou Ali AN, Salem KM, Alarcon LH, Bauza G, Pikoulis E, Chaer RA, et al. Vascular Shunts in Civilian Trauma. Front Surg [Internet]. 2017; 20;4:39.

25. Hornez E, Boddaert G, Ngabou UD, Aguir S, Baudoin Y, Mocellin N, et al. Temporary vascular shunt for damage control of extremity vascular injury: A toolbox for trauma surgeons. J Vasc Surg. 2015;152(6):363-8.

26. Inaba K, Aksoy H, Seamon MJ, Marks JA, Duchesne J, Schroll R, et al. Multicenter evaluation of temporary intravascular shunt use in vascular trauma. J Trauma Acute Care Surg. 2016;80(3):359-65. 